\title{
The Countermanding Task Revisited: Mimicry of Race Models
}

\author{
Patrick G. Bissett \\ Department of Psychology, Vanderbilt University, Nashville, Tennessee 37240 \\ Review of Salinas and Stanford.
}

The countermanding or stop-signal task involves making a response to a go stimulus, but stopping this response on a subset on trials when a stop signal occurs. As the delay between the go stimulus and the stop signal (stop-signal delay or SSD) increases, stopping becomes more difficult, because the go process has a larger headstart on the stop process. When subjects fail to stop on stop-signal trials, their responses tend to be faster than on trials without a stop signal. These results were explained with the independent race model (Logan and Cowan, 1984), which suggests that a go process, initiated at go stimulus onset, races independently against a stop process that is initiated at the stop signal. If the go process finishes first, subjects complete the go response; if stop finishes first, subjects stop. This model proposes that failed-stop reaction times (RTs) are faster than no-stop-signal RTs because only the fastest go responses escape inhibition.

The independent race model (Logan and Cowan, 1984) is formulated very generally to capture finishing time distributions, without any commitment to the underlying neural processes. It allows computation of stop-signal reaction time

Received May 16, 2013; revised June 14, 2013; accepted June 20, 2013.

This research was supported by National Eye Institute Grant R01EY021833-01. I thank Drs. Gordon D. Logan and Jeffrey D. Schall for their helpful comments and suggestions on this manuscript.

Correspondence should be addressed to Patrick G. Bissett, Department of Psychology, Vanderbilt University, 11121 st Avenue South, Nashville, TN 37240. E-mail: patrick.g.bissett@vanderbilt.edu.

DOI:10.1523/JNEUROSCI.2091-13.2013

Copyright $\odot 2013$ the authors $\quad 0270-6474 / 13 / 3312150-02 \$ 15.00 / 0$
(SSRT), which can be used to compare inhibitory control across age, patient groups, or experimental conditions.

Recent work has attempted to specify the neural underpinnings of stopping. Boucher et al. (2007) proposed the "interactive race model" in which neural inhibition is the mechanism for stopping. Neurophysiological data from the frontal eye fields and superior colliculus in monkeys performing a saccade stop task (Hanes et al., 1998; Paré and Hanes, 2003) and from premotor cortex of monkeys performing a manual stop task (Mirabella et al., 2011) demonstrated modulation of neural activity arising from a network of mutually inhibitory neurons. The interactive race model involves mutually inhibitory go and stop units. The go process is initiated by the go stimulus, there is a delay for go stimulus encoding, and then the go unit activates. Similarly, the stop process is initiated by the stop signal, there is a delay for stop stimulus encoding, and then the stop unit activates. Model fits showed that the stop unit potently inhibits the go unit very late in their processing. This produces finishing times that appear independent, as assumed by Logan and Cowan (1984), because the go and stop processes proceed independently for most of their duration.

Salinas and Stanford (2013) have now proposed a new model of stopping that emphasizes the time to perceive the stop stimulus. This work builds on the foundation of the compelled saccade task (Shankar et al., 2011), which attempts to separate the contribution of perceptual and motor pro- cessing in choice RT. Like in the interactive race model, Salinas and Stanford (2013) suggest that programming a saccade involves buildup to a threshold. When a stop signal occurs, it is detected with a particular speed and reliability by perceptual mechanisms. Once the stop signal is detected, the movement plan decelerates, stopping the movement. This model is a formal description of the necessary condition for a response to be stopped (the rate of go activation becomes zero), but there is no commitment to a mechanism that causes the rate to change. It could be inhibition, as others have suggested (Boucher et al., 2007; Lo et al., 2009; Wong-Lin et al., 2010).

Salinas and Stanford (2013) showed that this "cancellable rise-to-threshold" model, like the Boucher et al. (2007) model, replicates countermanding behavior and the dynamics of neural recordings. They also suggest a measure called raw processing time ( $\mathrm{rPT})$, which is calculated on each trial by subtracting SSD from RT. $\mathrm{rPT}$ is essentially the same as the relative finishing times (Logan, 1981) that motivated the race model (Logan and Cowan, 1984).

Salinas and Stanford (2013) emphasize the differences between their cancellable rise-to-threshold model and previous race models, but the similarities are so profound that the models are essentially the same mathematically. In both their model and the interactive race model (Boucher et al., 2007), a go stimulus initiates a delay for stimulus encoding and then a noisy accumulation process that takes a variable amount of time to reach threshold. In 
both models, a stop signal initiates a twostage process. First, there is a delay in which the go process and the stop signal do not interact $\left(D_{\text {stop }}\right.$ in interactive race and $\Delta_{\mathrm{s}}$ in cancellable rise-to-threshold). Second, after detecting the stop signal, the go activation is inhibited ( $B_{\text {stop }}$ in interactive race represents neural inhibition) or decelerated ( $\tau$ in cancellable rise-to-threshold represents the rate of deceleration). If go accumulation is stopped before reaching threshold, then subjects will not make a response. If go accumulation reaches threshold, subject will make a response. This applies to both models, revealing that these models are strikingly similar.

Recognizing that the models are very similar, Salinas and Stanford (2013) suggest an important difference: In race models, inhibition is all or none, but in their model it results from a gradual interaction. However, race models do not assume all-or-none inhibition. The independent race model (Logan and Cowan, 1984) makes no commitment about underlying neural inhibition. The interactive race model (Boucher et al., 2007) does not have all-or-none inhibition and the interaction between the go and stop units determines the winner. After a delay $\left(D_{\text {stop }}\right)$, the stop unit begins to accumulate activation and inhibit the go unit. The amount of inhibition of the go process by the stop process is determined by the product of the strength of inhibition $\left(B_{\text {stop }}\right)$ and the rising stop unit activity $\left(a_{\text {stop }}\right)$. This produces increasing inhibition in the period before the winner is determined. Fitting the interactive race model to data has suggested that inhibition from stop onto go is potent (Boucher et al., 2007), but potent inhibition is not all-or-none inhibition.

Salinas and Stanford (2013) suggest an experiment to distinguish between the independent race model (Logan and Cowan, 1984) and their cancellable rise-tothreshold model. They suggest a selective stop task in which a stop signal sometimes appears and remains and subjects stop, and other times appears momentarily then turns off (transient stop signal) and subjects respond. Salinas and Stanford (2013) suggest that in the cancellable rise-to-threshold framework, a transient stop signal would momentarily interrupt the go process, and then the interrupted go process would resume. They suggest that in the independent race model, the transient stop signal would completely stop the go process, and the go activation would be erased and restart from zero.

There are three problems with the proposed experiment. First, the independent race model only addresses finishing times and makes no predictions about the accumulation, reduction, or restarting of go or stop activation, so none of the possible outcomes of this experiment would be inconsistent with it. Second, the interactive race model could make essentially the same prediction as cancellable rise-tothreshold, because go activation remains high for a period of time after stop begins to inhibit go (see Boucher et al., 2007, Fig. 6f). Third, Gordon Logan and I have data that suggests that this experiment will not distinguish between race models and cancellable rise-to-threshold. We ran a selective stopping task that is like this proposed experiment (Bissett and Logan, 2013). This work was in press when the Salinas and Stanford (2013) paper was published. There was a choice go task and occasionally one of two stimuli occurred. One was the stop signal, which meant that subjects should inhibit their response. The other was an ignore signal, which meant that subjects should execute their speeded response to the go task. Some subjects approached the task by stopping whenever a stop or ignore signal occurred and then re-engaged their response on ignore trials. Go RT on ignore trials were faster than they would be if go activation reset from baseline. We assessed this by re-calculating go RT on ignore trials relative to the onset of the ignore stimulus. If activation was reset to baseline, then go RT relative to the onset of the ignore stimulus should be at least as slow as go RT on no-signal trials, but it was faster, so go activation cannot have been reset to baseline. This result is consistent with the independent race (Logan and Cowan, 1984), interactive race (Boucher et al., 2007) or cancellable rise-to-threshold models (Salinas and Stanford, 2013), suggesting that Salinas and Stanford's (2013) proposed experiment will not distinguish between alternative stopping models.

It appears that behavioral and neurophysiological data have not been able to distinguish between the interactive race (Boucher et al., 2007) and cancellable riseto-threshold (Salinas \& Stanford, 2013) models. One way that Salinas and Stanford (2013) distinguish between the two models is that race models involve inhibition but their model does not. Salinas and Stanford (2013) do not propose an alternative mechanism. Human neuroscientific work addresses whether stopping involves neural inhibition. Badry et al. (2009) used transcranial magnetic stimulation to show that when subjects stop hand movements, a pulse to the motor cortex suppresses the motor evoked potential bilaterally in both hands and legs. This suggests that stopping involves neuronal suppression across the motor cortex, supporting neural inhibition as the mechanism for stopping.

In summary, Salinas and Stanford (2013) presented a model to explain countermanding performance. It emphasizes that subjects must perceive the stop signal before acting on it, and it makes no assumptions about inhibitory mechanisms. But their model is essentially the same mathematically as previous neural models (Boucher et al., 2007; Lo et al. 2009; WongLin et al. 2010) that explain stopping, except that the interactive race model (Boucher at al., 2007) proposes a mechanism (inhibition) for how the go response is stopped. This suggests that the cancellable rise-tothreshold model does not improve on existing race models for the stop-signal task.

\section{References}

Badry R, Mima T, Aso T, Nakatsuka M, Abe M, Fathi D, Foly N, Nagiub H, Nagamine T, Fukuyama H (2009) Suppression of human corticomotoneuronal excitability during the Stop-signal task. Clin Neurophysiol 120:1717-1723. CrossRef Medline

Bissett PG, Logan GD (2013) Selective stopping? Maybe not. J Exp Psychol Gen. Advance online publication. Retrieved March 11, 2013. doi:10.1037/a0032122. CrossRef Medline

Boucher L, Palmeri TJ, Logan GD, Schall JD (2007) Inhibitory control in mind and brain: an interactive race model of countermanding saccades. Psychol Rev 114:376-397. CrossRef Medline

Hanes DP, Patterson WF 2nd, Schall JD (1998) The role of frontal eye field in countermanding saccades: visual, movement and fixation activity. J Neurophysiol 79:817-834. Medline

Lo CC, Boucher L, Paré M, Schall JD, Wang XJ (2009) Proactive inhibitory control and attractor dynamics in countermanding action: a spiking neural circuit model. J Neurosci 29:9059-9071. CrossRef Medline

Logan GD (1981) Attention, automaticity, and the ability to stop a speeded choice response. In: Attention and performance IX (Long J and Baddeley AD, eds), pp 205-222. Hillsdale, NJ: Erlbaum.

Logan GD, Cowan WB (1984) On the ability to inhibit thought and action: a theory of an act of control. Psychol Rev 91:295-327. CrossRef

Mirabella G, Pani P, Ferraina S (2011) Neural correlates of cognitive control of reaching movements in the dorsal premotor cortex of rhesus monkeys. J Neurophysiol 106:1454-1466. CrossRef Medline

Paré M, Hanes DP (2003) Controlled movement processing: superior colliculus activity associated with countermanded saccades. J Neurosci 23:6480-6489. Medline

Salinas E, Stanford TR (2013) The countermanding task revisited: fast stimulus detection is a key determinant of psychophysical performance. J Neurosci 33:5668-5685. CrossRef Medline

Shankar S, Massoglia DP, Zhu D, Costello MG, Stanford TR, Salinas E (2011) Tracking the 
temporal evolution of a perceptual judgment using a compelled-response task. J Neurosci 31:8406-8421. CrossRef Medline
Wong-Lin K, Eckhoff P, Holmes P, Cohen JD (2010) Optimal performance in a counter- manding saccade task. Brain Res 1318:178-187. CrossRef Medline 